\title{
Использование платформы iNaturalist в образовательном процессе
}

\author{
Д.Р. Владимиров ${ }^{凶}$, В. И. Айникеева, А. В. Лаенко, \\ Я.Д. Богунова, Н.С. Спиридонова, И.В. Корякова \\ Воронежский государственный университет, Российская Федераџия \\ (394018, г. Воронеж, Университетская пл., 1)
}

\begin{abstract}
Аннотация: Цель - рассмотреть практические результаты применения электронной платформы iNaturalist в ходе прохождения дисциплин «Биогеография», «Биоразнообразие» и «Ландшафтно-экологической учебной практики».

Maтериалы и методы. В основе социальная сети iNaturalist лежит концепция картографирования биологического разнообразия с обменом данными наблюдателей со всего мира. Важным условием включения наблюдений в научный оборот является их соответствие минимальным требованиям (дата, географические координаты места встречи, наличие авторской фотографии/серии фотографий организма или аудиозапись его голоса, нахождение в природе) и выбор свободной лицензии.

Результаты и обсуждение. За время прохождения учебной практики загружены 5028 наблюдений 641 вида. Кроме широко распространенных аборигенных растений в их число попали инвазионные и редкие растения. Большую ценность представляют 22 находки видов Красной книги России и Воронежской области, в том числе 14 из новых местонахождений.

Заключение. Возможности искусственного интеллекта iNaturalis и оперативность определения организмов экспертным сообществом являются преимуществом платформы. К недостаткам относятся ограничения, связанные с отображением анатомических, микроморфологических и других признаков, необходимых для точной идентификации некоторых таксонов.
\end{abstract}

Ключевые слова: iNaturalist, биоразнообразие, COVID-19, Красная книга.

Для цитирования: Владимиров Д.Р., Айникеева В.И., Лаенко А.В., Богунова Я.Д., Спиридонова Н.С., Корякова И.В. Использование iNaturalist в образовательном процессе // Вестник Воронежского государственного университета. Серия: География. Геоэкология, 2021 № 2, с. 80-85. DOI: https://doi.org/10.17308/geo.2021.2/3451

\section{ВВЕДЕНИЕ}

Распространение весной 2020 короновирусной инфекции привело к изменению режима работы образовательных организаций России. 14 марта Министерство науки и высшего образования РФ рекомендовало всем вузам страны перейти на дистанционное обучение. Воронежский государственный университет (ВГУ) за несколько лет до этих событий начал внедрять цифровые технологии и сервисы в учебный процесс и профессорско-преподавательский состав уже имел опыт разработки и внедрения онлайн-курсов.

Активное вовлечение студентов и преподавателей в дистанционный формат обучения на факультете географии, геоэкологии и туризма ВГУ началось во второй половине марта 2020 года [1]. Так, дисциплины «Биогеография» и «Биоразнообразие», а также «Ландшафтно-экологическая учебная практика» у студентов 2 курса направления «Экология и природопользование» реализовывались на базе образовательной платформы Moodle. Задачами учебных дисциплин является формирование представлений о географическом распространении биологического разнообразия, знакомство с закономерностями формирования и структуры растительного покрова отдельных регионов и Земли в целом, а для учебной практики - овладение методикой комплексных полевых ландшафтных исследований, включая описание биоты, как компонента ландшафта. Если раньше

(C) Владимиров Д.Р., Айникеева В.И., Лаенко А. В., Богунова Я. Д., Спиридонова Н. С., Корякова И. В., 2021

$\varangle$ Владимиров Дмитрий Романович, e-mail: kvint 88@mail.ru

Контент доступен под лицензией Creative Commons Attribution 4.0 License. 
для выполнения этих задач использовался учебный фонд гербария факультета географии, геоэкологии и туризма (VORG), а также проводились ботанико-географические экскурсии, то в 2020 году удаленный режим работы не позволил этого сделать.

\section{МАТЕРИАЛЫ И МЕТОДЫ}

Современные дистанционные образовательные технологии позволили адаптировать учебный процесс к ограничениям пандемии. Для знакомства студентов с биологическим разнообразием (в первую очередь с флористическим разнообразием) России на практике, в качестве дополнения к платформе Moodle, применялась социальная сеть профессиональных ученых и любителей природы iNaturalist, в основе которой лежит концепция картографирования биологического разнообразия с обменом данными наблюдателей со всего мира. База данных этой платформы сейчас включает в себя около 60 млн. наблюдений, а в ее работе участвуют 1,5 млн. человек. Любой желающий может зарегистрироваться в качестве её пользователя и загрузить через учетную запись наблюдения, используя веб-сайт www.inaturalist.org или его бесплатное мобильное приложение.

Чтобы наблюдение использовать в научном обороте, необходимо его соответствие минимальным требованиям, включающим: дату, географические координаты места встречи, наличие авторской фотографии/серии фотографий организма или аудиозапись его голоса, нахождение в природе. Если наблюдение удовлетворяет этим условиям, то попадает в число «неопределенных», даже если автор идентифицировал вид. Когда оно определено до вида как минимум двумя экспертами, то получает «исследовательский уровень» и переходит в категорию верифицированных [2].

Каждый пользователь iNaturalist выбирает лицензию для своих наблюдений, которая определяет тип их дальнейшего использования. При выборе свободных лицензий Creative Commons (CC0, CC-BY или CC-BY-NC) данные, достигшие «исследовательского уровня», автоматически экспортируются в Глобальный информационный фонд по биоразнообразию «Global Biodiversity Information Facility» ${ }^{1}$ и окончательно включаются в научный оборот [2].

Важным достоинством iNaturalist можно считать наличие самообучающегося искусственного интеллекта. Он предлагает пользователю наибо- лее схожие внешне виды в качестве подсказки при определении. Еще одной сильной стороной платформы является возможность создания проектов, автоматически объединяющих наблюдения по интересующим создателя критериям. На главной странице каждого проекта отображается его основаная статистика, включающая общее число наблюдений, количество биологических видов, число экспертов, принявших участие в идентификации организмов и иная информация.

Студентам было предложено создать учетные записи на платформе iNaturalist в начале изучения дисциплин «Биогеография» и «Биоразнообразие» и добавить не менее 100 наблюдений растений до конца семестра. Трудностей при работе с платформой и выполнении задания не возникло, поэтому было решено использовать ее и при прохождении биогеографической части «Ландшафтно-экологической учебной практики». С этой целью доцент Д.Р. Владимиров создал проект «Ландшафтно-экологическая учебная практика Воронежского государственного университета», куда прикреплялись студенты-практиканты. Отметим, что кроме ВГУ для проведения учебных практик в 2020 году возможностями iNaturalist воспользовались и другие вузы, в том числе Московский государственный университет, Иркутский государственный университет и Казанский федеральный университет.

\section{РЕЗУЛЬТАТЫ И ОБСУЖДЕНИЕ}

Загрузка фотоматериалов в ходе практики продолжалась с 4 по 20 июля. За это время участники проекта добавили 5028 наблюдений 641 вида высших растений, в определении которых приняли участие 165 экспертов из России, стран Европы и США. География проекта распространялась от Тульской области на севере до Краснодарского края и Астраханской области на юге, но большинство наблюдений были сделаны в Воронежской области.

Чаще всего студенты регистрировали широко распространенные в Средней России сорные виды (латинские названия и фамилии авторов таксонов приведены по базе данных «Plants of the World online» ${ }^{2}$, в скобках () указано общее число находок): Echium vulgare L. (77), Convolvulus arvensis L. (67), Cichorium intybus L. (64) и Cirsium arvense (L.) Scop. (59). Кроме того, среди растений, вошедших в первую сотню проекта, было много инвазионных видов. Например, Erigeron canadensis L.

\footnotetext{
${ }^{1} \mathrm{http}: / /$ www.gbif.org

${ }^{2} \mathrm{http} / / / \mathrm{www}$. theplantlist.org
} 
(55), Lactuca serriola L. (40), Saponaria officinalis L. (33), Parthenocissus quinquefolia (L.) Planch. (22), Cyclachaena xanthiifolia (Nutt.) Fresen. (21), Erigeron annuus (L.) Pers. (20), Lactuca tatarica (L.) C.A.Mey. (19), Impatiens parviflora DC. (17), Oenothera biennis L. (17), Amaranthus retroflexus L. (16), Acer negundo L. (15), Sambucus racemosa L. (15), Setaria viridis (L.) P.Beauv. (15).

Отдельного рассмотрения заслуживают находки редких и «краснокнижных» видов растений. Среди них наибольшую ценность имеют наблюдения из ранее неизвестных специалистам местонахождений (помечены звездочкой *). Ниже приведены наблюдения видов Красной книги Воронежской области [3] (для Липецкой, Волгоградской областей и Краснодарского края сведения будут опубликованы позднее). Все они имеют географические координаты, название муниципального района/городского округа и ближайшего к месту наблюдения населенного пункта, местообитание, дату наблюдения, фамилию наблюдателя, URL-ссылка наблюдения на платформе iNaturalist.

\section{Clematis integrifolia L.:}

1) *51.551067 N, $39.00522 \mathrm{E}$, Хохольский район, окр. с.Устье, лесной массив восточнее села, 14.05.2020, наблюдатель В. Айникеева, iNaturalist-наблюдение: https://www.inaturalist.org/ observations/45865352

\section{Schult.f.:}

Fritillaria meleagroides Patrin ex Schult. \&

2) *51.062124 N, 41.624196 Е, Новохоперский район, окр. пос. Плаутино, северо-западная окраина поселка, пойменный луг, 04.05.2020, наблюдатель А. Лаенко, iNaturalist-наблюдение:

https://www.inaturalist.org/observations/44860126

3) $* 50.998368 \mathrm{~N}, 39.346093 \mathrm{E}$, Лискинский район, окр. с. Копанище, 400 м южней села, пойменный луг, 15.05.2020, наблюдатель Н. Полякова, iNaturalist-наблюдение: https://www.inaturalist. org/observations/45998158

4) *51.104426 N, 41.65975 Е, Новохоперский район, окр. х. Замельничный, лес в 250 м южней хутора, 17.05.2020, наблюдатель А. Лаенко, iNaturalist-наблюдение: https://www.inaturalist.org/ observations/46234188

\section{Iris aphylla L.:}

5) *51.648791 N, $39.428022 \mathrm{E}$, Новоусманский район, окр. с. Новая Усмань, лес восточней ул. Тенистая, 22.04.2020, наблюдатель В. Айникеева, iNaturalist-наблюдение: https://www.inaturalist.org/ observations $/ 42830060$
6) *51.554752 N, $39.015665 \mathrm{E}$, Хохольский район, окр. с. Устье, лесной массив восточнее села, 14.05.2020, наблюдатель В. Айникеева, iNaturalist-наблюдение: https://www.inaturalist.org/ observations $/ 45867350$

7) $51.705438 \mathrm{~N}, 39.21426$ Е, городской округ г. Воронеж, северная окраина Центрального парка, в лесу, 16.05.2020, наблюдатель М. Зимина, iNaturalist-наблюдение: https://www.inaturalist.org/ observations/46077649

\section{Iris pumila L.:}

8) *50.2496 N, 41.243789 Е, Калачеевский район, окр. с. Новая Криуша, меловые склоны в 500 м западней села, 10.04.2020, наблюдатель К. Жуков, iNaturalist-наблюдение: https://www.inaturalist.org/ observations/41828232

Matteuccia struthiopteris (L.) Tod.:

9) $51.111003 \mathrm{~N}, 41.615916$ Е, Новохоперский район, ХГПЗ, на севере кв.185, в лесу, 24.05.2020, наблюдатель А. Лаенко, iNaturalist-наблюдение: https://www.inaturalist.org/observations/47145044

10) $51.165355 \mathrm{~N}, 41.736216$ E, Новохоперский район, кв. 147/149, в лесу, 12.05.2020, наблюдатель А. Лаенко, iNaturalist-наблюдение: https://www.inaturalist.org/observations/45704404

Memoremea scorpioides (Haenke) A.Otero, Jim.Mejías, Valcárcel \& P.Vargas:

11) *51.557409 N, 39.011075 Е, Хохольский район, окр. с. Устье, лесной массив восточнее села, 23.04.2020, наблюдатель В. Айникеева, iNaturalist-наблюдение: https://www.inaturalist.org/ observations/42949516

Ornithogalum orthophyllum subsp. kochii (Parl.) Zahar. (Ornithogalum kochii Parl.):

12) *50.16451 N, 39.559404 E, Россошанский район, северная окраина пос. Опытной плодово-ягодной станции, среди деревьев, 13.05.2020, наблюдатель Я. Богунова, iNaturalist-наблюдение: https://www.inaturalist.org/observations/45792151

Pulsatilla patens (L.) Mill.:

13) $51.890452 \mathrm{~N}, 39.59072$ Е, Верхнехавский район, окр. ст. Графская, 400 м северней, на опушке леса, 27.03.2020, наблюдатель И. Корякова, iNaturalist-наблюдение: https://www.inaturalist.org/ observations $/ 40822133$

14) 51.814647 N, 39.561732 Е, Верхнехавский район, окр. с.Углянец, 350 м западней села, на опушке леса, 29.03.2020, наблюдатель Н. Спиридонова, iNaturalist-наблюдение: https://www. inaturalist.org/observations/40960451

\section{Pulsatilla pratensis (L.) Mill.:}

15) *51.075572 N, 41.624122 Е, Новохоперский район, лес рядом с дорогой между г. Новохоперск 
и ст. Плаутино, 04.05.2020, наблюдатель А. Лаенко, iNaturalist-наблюдение: https://www.inaturalist. org/observations/44861575

\section{Salvia aethiopis L.:}

16) *50.248802 N, 41.230377 Е, Калачеевский район, окр. с. Новая Криуша, меловые склоны в 1 км западней села, 10.04.2020, наблюдатель К. Жуков, iNaturalist-наблюдение: https://www. inaturalist.org/observations/41824875

17) *50.163967 N, 39.559546 Е, Россошнанский район, северная окраина пос. Опытной плодово-ягодной станции, среди деревьев, 13.05.2020, наблюдатель Я. Богунова, iNaturalist-наблюдение: https:/www.inaturalist.org/observations/45788970

Tulipa sylvestris subsp. australis (Link) Pamp. (Tulipa biebersteiniana Schult. \& Schult.f.):

18) *50.248337 N, 41.250323 Е, Калачеевский район, окр. с. Новая Криуша, лес на правобережной пойме р. Криуша, 10.04.2020, наблюдатель К. Жуков, iNaturalist-наблюдение: https://www. inaturalist.org/observations/41829495

19) *50.267393 N, 41.299341 Е, Калачеевский район, окр. с. Новая Криуша, склон за участковой больницей, 29.04.2020, наблюдатель К. Жуков. Новое местонахождение вида для района, iNaturalist-наблюдение: https://www.inaturalist.org/ observations/44261791

Vaccinium myrtillus L.:

20) 51.834244 N, 39.588629 E, Верхнехавский район, окр. с. Углянец, 300 м северней, в лесу, 17.03.2020, наблюдатель Н. Спиридонова, iNaturalist-наблюдение: https://www.inaturalist.org/ observations/40119266

21) $51.892432 \mathrm{~N}, 39.593013$ Е, Верхнехавский район, окр. ст. Графская, 450 м северней, в лесу, 17.05.2020, наблюдатель И. Корякова, iNaturalist-наблюдение: https://www.inaturalist.org/ observations/46261164

Vaccinium vitis-idaea L.:

22) $51.834242 \mathrm{~N}, 39.588685$ Е, Верхнехавский район, окр. с.Углянец, 450 м северней, в лесу, 17.03.2020, наблюдатель Н. Спиридонова, iNaturalist-наблюдение: https://www.inaturalist.org/ observations/40120804

Всего было зарегистрировано 14 новых местонахождений видов растений Красной книги Воронежской области (Красная книга..., 2018) и 4 Красной книги России (Iris aphylla, Iris pumila, Pulsatilla pratensis) [4]. Новые местонахождения видов позволяют уточнить структуру их ареалов в границах Воронежской области и служат для дальнейшего совершенствования региональной Красной книги.

\section{ЗАКЛЮЧЕНИЕ}

Подводя предварительные итоги использования iNaturalist в учебном процессе, отметим большой интерес к платформе со стороны студентов, которые по достоинству оценили возможности ее искусственного интеллекта, а также оперативность определения организмов экспертным сообществом. Конечно, полагаться исключительно на нее нельзя, ведь существуют группы, идентификация которых невозможна без выявления анатомических, микроморфологических и других трудно передаваемых или не передаваемых на фотографии признаков. В том числе по этой причине в число наблюдений «краснокнижных» растений не были включены перистые ковыли (секция Stipa рода Stipa), хотя и были загружены их наблюдения.

Наблюдения воронежских студентов пополнили данные портала для автоматического анализа данных по региональным проектам, посвященным сосудистым растениям нашей страны «Флора России», цель которого сбор информации о современном флористическом разнообразии России.

Благодарности: авторы благодарят студентов 2 курса направления «Экология и природопользование» за активную работу на платформе iNaturalist и их неподдельный интерес к изучению биологического разнообразия России.

\section{СПИСОК ЛИТЕРАТУРЫ}

1. Куролап С.А. Дистанционное образование: методические аспекты и практический опыт организации на факультете географии, геоэкологии и туризма // Вестник Воронежского государственного университета. Серия География. Геоэкология, 2020, № 4, с. 7984. DOI: https://doi.org/10.17308/geo.2020.4/3068.

2. Серегин А.П. «Флора России» на платформе iNaturalist: большие данные о биоразнообразии большой страны / А.П. Серегин [и др.] // Журнал общей биологии, 2020, т. 81, № 3, с. 223-233.

3. Красная книга Воронежской области: в 2 т. Т. 1: Растения. Лишайники. Грибы / под ред. В. А. Агафонова. Воронеж: Центр духовного возрождения Черноземного края, 2018. $412 \mathrm{c}$.

4. Красная книга Российской Федерации (растения и грибы) / Отв. ред. Л.В. Бардунов, В.С. Новиков. М.: Тов-во науч. изд. КМК, 2008. 856 с.

Конфликт интересов: Авторы декларируют отсутствие явных и потенциальных конфликтов интересов, связанных с публикацией настоящей статьи.

Поступила в редакцию 29.03.2021 Принята к публикации 28.05.2021 


\title{
Use of the Social Network iNaturalist in the Educational Process
}

\author{
D. R. Vladimirov ${ }^{\varpi}$, V. I. Inikeeva, A. V. Laenko, \\ Ya. D. Bogunova, N. S. Spiridonova, I. V. Koryakova \\ Voronezh State University, Russian Federation \\ (1, Universitetskaya sq., Voronezh, 394018)
}

\begin{abstract}
Purpose: to consider practical results of iNaturalist electronic platform use in courses of "Biogeography", "Biodiversity" and "Landscape-ecological student practice".

Materials and methods. iNaturalist social network bases on a concept of biodiversity mapping with data exchange from observers from around the globe. An important condition for observations inclusion in scientific circulation is their compliance with the minimum requirements (date, geographical coordinates of an observation, author's photograph/series of photographs of an organism or an audio record of its voice, being in nature) and a choice of a free license.

Results and discussion. During the student practice about 5028 observations of 641 species were loaded. In addition to widespread indigenous plants, invasive and rare plants included in their number. Of great value are 22 finds of species from Red Data Book of Russia and Voronezh oblast, including 14 from new habitats.

Conclusion. Capabilities of iNaturalis artificial intelligence and efficiency of organisms identifying by the expert community are the advantages of the platform. The disadvantage is limitations associated with a display of anatomical, micromorphological and other features necessary for an accurate identification of some taxa.
\end{abstract}

Key words: iNaturalist, biodiversity, COVID-19, Red Data Book.

For citation: Vladimirov D.R., Inikeeva V.I., Laenko A. V., Bogunova Ya.D., Spiridonova N.S., Koryakova I.V. Use of the Social Network iNaturalist in the Educational Process. Vestnik Voronezskogo gosudarstvennogo universiteta. Seria: Geografia. Geoekologia, 2021, no. 2, pp. 80-85. (In Russ.). DOI: https://doi.org/10.17308/geo.2021.2/3451

\section{REFERENCES}

1. Kurolap S.A. Distantsionnoe obrazovanie: metodicheskie aspekty i prakticheskiy opyt organizatsii na fakul'tete geografii, geoekologii i turizma [Distance Education: Methodological Aspects and Practical Experience of Organization in the Faculty of Geography, Geoecology and Tourism]. Vestnik Voronezhskogo gosudarstvennogo universiteta. Seria: Geografia. Geoekologia, 2020, no. 4, pp. 79-84. (In Russ.) DOI: https://doi.org/10.17308/geo.2020.4/3068.

2. Seregin A.P. «Flora Rossii» na platforme iNaturalist: bol'shie dannye o bioraznoobrazii bol'shoy strany / A.P. Seregin [i dr.] ["Flora of Russia" on the Inaturalist platform: large data on biodiversity big country]. Zhurnal obshchey biologii, 2020, vol. 81, no. 3, pp. 223-233.
3. Krasnaya kniga Voronezhskoy oblasti: v 2 tomakh. T. 1: Rasteniya. Lishayniki. Griby / pod red. V.A. Agafonova [Red Book of the Voronezh region: in 2 volumes. T. 1: Plants. Lichens. Mushrooms]. Voronezh: Tsentr dukhovnogo vozrozhdeniya Chernozemnogo kraya, 2018. 412 p.

4. Krasnaya kniga Rossiyskoy Federatsii (rasteniya i griby) / Otv. red. L. V. Bardunov, V. S. Novikov [Red Book of the Russian Federation (Plants and Mushrooms)]. M.: Tov-vo nauch. izd. KMK, 2008. 856 p.

Conflict of interests: The authors declare no information of obvious and potential conflicts of interest related to the publication of this article.

Received: 29.03.2021

Accepted: 28.05.2021

(C) Vladimirov D. R., Inikeeva V.I., Laenko A. V., Bogunova Ya. D., Spiridonova N. S., Koryakova I. V., 2021 $\triangle$ Dmitry R. Vladimirov, e-mail: kvint_88@mail.ru

The content is available under Creative Commons Attribution 4.0 License. 
Владимиров Дмитрий Романович

кандидат географических наук, доцент кафедры рекреационной географии, страноведения и туризма факультета географии, геоэкологии и туризма Воронежского государственного университета, г. Воронеж, Российская Федерация, ORCID: 0002-8401-7816, e-mail: kvint_88@mail.ru

Айникеева Валентина Игоревна

Студентка 3 курса кафедры геоэкологии и мониторинга окружающей среды факультета географии, геоэкологии и туризма Воронежского государственного университета, Воронеж, Российская Федерация, e-mail: zaiac22.03@mail.ru

Лаенко Анна Владимировна

Студентка 3 курса кафедры природопользования географического факультета, геоэкологии и туризма Воронежского государственного университета, Воронеж, Российская Федерация, e-mail: annalaenko@gmail.com

Богунова Яна Дмитриевна

Студентка 3 курса кафедры геоэкологии и мониторинга окружающей среды факультета географии, геоэкологии и туризма Воронежского государственного университета, Воронеж, Российская Федерация, e-mail: bogunova.yana@mail.ru

Спиридонова Надежда Сергеевна

Студент 3 курса кафедры геоэкологии и мониторинга окружающей среды факультета географии, геоэкологии и туризма Воронежского государственного университета, Воронеж, Российская Федерация, e-mail: nadjaugl@mail.ru

Корякова Ирина Валерьевна

Студентка 3 курса кафедры геоэкологии и мониторинга окружающей среды факультета географии, геоэкологии и туризма Воронежского государственного университета, Воронеж, Российская Федерация, e-mail: koriakova2014@gmail.com
Dmitry R. Vladimirov

Cand. Sci. (Geogr.), Associate Professor of the Department of Recreational Geography, Country Studies and Tourism, Faculty of Geography, Geoecology and Tourism, Voronezh State University, Voronezh, Russian Federation, ORCID: 0002-8401-7816, e-mail: kvint_88@mail.ru

Valentina I. Inikeeva

$3^{\text {rd }}$ year student of the Department of Geoecology and Environmental Monitoring, Faculty of Geography, Geoecology and Tourism, Voronezh State University, Voronezh, Russian Federation, e-mail: zaiac22.03@mail.ru

Anna V. Laenko

$3^{\text {rd }}$ year student of the Department of Nature Management, Faculty of Geography, Geoecology and Tourism, Voronezh State University, Voronezh, Russian Federation, e-mail: annalaenko@gmail.com

Yana D. Bogunova

$3^{\text {rd }}$ year student of the Department of Geoecology and Environmental Monitoring, Faculty of Geography, Geoecology and Tourism, Voronezh State University, Voronezh, Russian Federation, e-mail: bogunova.yana@mail.ru

Nadezhda S. Spiridonova

$3^{\text {rd }}$ year student of the Department of Geo-Ecology and Environmental Monitoring, Faculty of Geography, Geoecology and Tourism, Voronezh State University, Voronezh, Russian Federation, e-mail: nadja-ugl@mail.ru

Irina $\mathrm{V}$. Koryakova

$3^{\text {rd }}$ year student of the Department of Geo-Ecology and Environmental Monitoring, Faculty of Geography, Geoecology and Tourism, Voronezh State University, Voronezh, Russian Federation, e-mail: koriakova2014@ gmail.com 